\section{A revolução demográfica dos povos indígenas no Brasil: a experiência dos Kayabí do Parque Indígena do Xingu, Mato Grosso, Brasil, 1970-2007}

\author{
The demographic revolution among Brazilian \\ indigenous peoples: the case of the Kayabí in \\ the Xingu Indian Reservation, Mato Grosso State, \\ Brazil, 1970-2007
}

Heloisa Pagliaro ${ }^{1}$

\section{Introdução}

This paper analyzes the demographic dynamics of the Kayabi, a Tupi people in the Xingu Indian Reservation in Central Brazil, from 1970 to 2007. Data were gathered from vital statistics for the Xingu Indian Reservation at the Federal University in São Paulo. Contact with Brazilian national society from 1920 to 1950 in the Upper Teles Pires River Valley led to a population decrease due to clashes and epidemics. In 1952, part of the Kayabi group gradually began migrating to the Xingu, where they still live. In 1970 there were 204 Kayabi in Xingu villages, and by 2007 there were 1,162, representing a $4.8 \%$ annual growth rate. For 2000-2007 the crude birth rate was 51 per thousand inhabitants; total fertility rate 7.8 children per women; crude death crude 3.5 per thousand inhabitants; and infant mortality rate $17.5 \mathrm{per}$ thousand live births. The majority of the population is under 15 years of age (55.9\%). The results show a population recovery process, similar to that of some other indigenous group in Brazil.

South Americans Indians; Population Dynamics; Demography
Desde os anos de 1500, quando diferentes estimativas contaram entre 800 mil e 2,5 milhões de índios no Brasil, até o início do século XX, a população indígena decresceu continuamente, reduzindo-se a 230 povos e 100 mil habitantes em 1900 1. Estima-se que durante esse período 85\% das línguas indígenas tenham desaparecido. Para a década de 1950, Ribeiro 2 estimou em 143 o número de etnias indígenas e uma população entre 67 e 98 mil habitantes.

As perspectivas de provável desaparecimento dos povos indígenas no país perduraram durante um longo período de tempo e, na década de 1970, indícios de crescimento de alguns povos sinalizaram para a reversão desta tendência ${ }^{3}$. Atualmente, existem 225 povos indígenas e uma população que varia entre 540 e 730 mil habitantes, conforme a Fundação Nacional de Saúde (FUNASA; http://www.funasa.gov.br, acessado em 03/Abr/2009) e o Instituto Brasileiro de Geografia e Estatística (IBGE) 4, respectivamente.

O crescimento da população indígena verificado nas últimas décadas constitui um evento de grande importância na história desses povos e do país, surpreendendo antropólogos e demais estudiosos dessas populações habituados à idéia do "descenso demográfico secular" e o provável desaparecimento com a assimilação dos índios à sociedade nacional 1,2,5. As razões ou causas desse surpreendente evento são múltiplas e vêm 
sendo exploradas em muitas investigações levadas a efeito no campo da antropologia e da demografia indígena no Brasil 6 . A redução dos níveis de mortalidade, especialmente a infantil, que, embora permaneçam ainda extremamente elevados, contribuiu sobremaneira para o aumento da sobrevivência de recém-nascidos, jovens e adultos de muitas etnias. Esse fator, combinado à manutenção ou à elevação dos níveis de fecundidade dessas populações, resultou em expressivo crescimento vegetativo, próximo de $3,5 \%$ ao ano, em muitas etnias. Como ocorre nessa fase do processo de transição demográfica, quando as populações, em geral, passam de decrescentes ou estáveis para populações em crescimento acelerado, assiste-se no presente momento a um rejuvenescimento importante das populações indígenas. Em muitos povos indígenas, a proporção de menores de 15 anos de idade supera atualmente a casa dos $50 \%$. Deve ser destacado que a melhoria das condições de saúde dessas populações tem propiciado o aumento da sobrevivência em todas as idades, repercutindo inclusive na elevação da proporção de maiores de 50 anos, contribuindo assim para a preservação de normas e valores culturais tradicionalmente transmitidos pelos velhos 7 .

Os elevados níveis de fecundidade vigentes nos últimos decênios poderiam representar a recuperação de padrões reprodutivos ancestrais 8 , existindo evidências de que nessas populações tais padrões seriam compatíveis com os seus anseios e necessidades estratégicas de poder e ocupação de território. Os povos indígenas organizados tenderiam a ter domínio sobre o tamanho da família e da população que desejassem para obter um tamanho mínimo de população que lhes permitisse fazer face às necessidades inerentes ao funcionamento de seus diferentes e complexos sistemas de organização social, como avaliado por Ribeiro ${ }^{5} \mathrm{em}$ análise dos efeitos dissociativos da depopulação de diversos povos indígenas no Brasil. Muitos povos detêm práticas de restrição voluntária de nascimentos, como tabus sexuais no pós-parto, desmame tardio, ervas anticoncepcionais de efeito temporário ou definitivo, práticas abortivas naturais e mecânicas, o que lhes permitiria controlar o tamanho de suas populações 9 .

Este estudo visa a analisar a dinâmica demográfica dos Kayabí, habitantes do Parque Indígena do Xingu, no período 1970-2007, de forma a contribuir para a ampliação do conhecimento demográfico sobre os povos indígenas no Brasil.

\section{História recente dos Kayabí}

Os Kayabí são um dos quatro povos de filiação lingüística Tupi, além dos Jurúna (Yudjá), Kamayurá e Awetí, que habitam o Parque Indígena do Xingu. Até meados do século XX, os Kayabí ocupavam a região do Alto rio Teles Pires, desde a confluência do rio Verde até o rio Peixoto de Azevedo, além de parte da bacia do rio dos Peixes, afluente da margem direita do Arinos (Mato Grosso). A partir da década de 1950, começaram a se deslocar para o Parque Indígena do Xingu, num movimento migratório que durou aproximadamente vinte anos.

As primeiras notícias sobre os Kayabí, muitas vezes confundidos com índios de outras etnias, datam do século XIX, quando expedições científicas e etnográficas percorreram a região do Mato Grosso e encontraram seus vestígios ou relataram referências feitas por seus inimigos tradicionais, como os Mundurukú e os Bakairi 10. Os contatos dos Kayabí com a sociedade envolvente se intensificaram quando a exploração da borracha, na região do rio Tapajós (Pará), se estendeu ao Mato Grosso e atingiu as nascentes dos rios Arinos e Teles Pires. A partir da década de 1940, por ocasião do terceiro boom da borracha e do enfraquecimento do Serviço de Proteção aos Índios (SPI), os seringais do Alto Teles Pires avançaram rapidamente sobre o território Kayabí, obrigando-os a mudar suas aldeias para o médio curso deste rio. O saldo dessa convivência foram epidemias de doenças infecto-contagiosas, depopulação, deslocamento contínuo de aldeias e fracionamento do grupo. Em 1950, os Kayabí estavam distribuídos geograficamente em três grupos: do Teles Pires (Mato Grosso), localizado entre a confluência dos rios Verde e Peixoto de Azevedo; do rio dos Peixes (Mato Grosso), entre este rio e o Arinos; do rio Cururuzinho (Pará), no Posto Indígena Kayabí11. No início dos anos 50 12, alguns Kayabí começaram a se deslocar em pequenos grupos para a região do Xingu, instalando-se a princípio na confluência dos rios Arraias e Manitsawa-Missu, e mais tarde, nas proximidades do Posto Indígena Diauarum, no médio curso do rio Xingu, onde se fixaram. Em 1966, uma expedição coordenada pelos irmãos Villas Bôas, integrada por alguns Kayabí habitantes do Xingu, resgatou 44 Kayabí das aldeias do rio dos Peixes, levando-os ao Parque Indígena do Xingu. Apenas vinte sobreviventes lá permaneceram para salvaguardar as sepulturas dos parentes e garantir a posse das terras, que já estavam sendo mensuradas para projetos de colonização.

A população Kayabí contava, em 1955 10, 341 indivíduos, distribuídos entre as aldeias dos rios Teles Pires, Peixes e Xingu e nos Postos Indígenas 
José Bezerra e Kayabí (Mato Grosso e Pará), do SPI. Em 1963, havia 126 Kayabí residindo em pequenas aldeias situadas ao longo do médio curso do rio Xingu, e nos Postos Indígenas Diauarum e Leonardo 13. Em 1966, Grunberg 10 recenseou 179 Kayabí no Xingu.

O processo migratório de aproximadamente vinte anos de duração se completou com o deslocamento de alguns integrantes do grupo do rio Cururuzinho, em 1973 12. Em realidade, as idas e vindas dos Kayabí, dos rios Teles Pires e Peixes para o Xingu e vice-versa, nunca cessaram. Nos mais de cinqüenta anos que se seguiram ao início do processo migratório, eles continuaram se deslocando em pequenos grupos para visitar os parentes, como outrora o faziam no imenso território onde habitavam. Ainda hoje, os Kayabí do rio dos Peixes lamentam ter abandonado as suas terras, as sepulturas de seus ancestrais, a matéria prima apropriada para o trançado de cestarias, a madeira mais apropriada para a confecção de arcos e flechas e as espécies animais e vegetais que não encontram na natureza xinguana 14 . Fizeram inúmeros projetos de retorno ao território ancestral. Alguns chegaram a concretizá-los, mas poucos o fizeram definitivamente - se consolam ao ver suas famílias crescendo e em garantir as terras em que vivem no Xingu.

Transcorrido mais de meio século da chegada dos primeiros Kayabí ao Xingu, observa-se que a mudança lhes permitiu crescer em população, preservar a identidade cultural e evitar a sorte comum à maior parte dos povos indígenas no Brasil, como a frágil integração no mercado de trabalho rural ou urbano.

\section{Material e métodos}

O estudo é do tipo descritivo de corte transversal e contempla análises por períodos seqüenciais entre 1970 e 2007.

Os dados quantitativos básicos foram extraídos das fichas médicas usadas no trabalho de campo do Programa de Saúde da Universidade Federal de São Paulo/Escola Paulista de Medicina (UNIFESP/EPM) no Parque Indígena do Xingu, a partir de 1966. Cada ficha médica contém: número de registro, data de abertura, foto de identificação, nome, sexo, idade, nome e número de registro dos pais, cônjuge(s) e filhos, dados dos exames médicos, vacinas aplicadas, intercorrências clínicas observadas em várias ocasiões, data e causa de óbito.

A atualização contínua desse arquivo, desde 1965, e a qualidade das suas informações permitiram identificar os eventos demográficos ocorridos entre os Kayabí do Xingu de 1970 a 2007, bem como reconstruir a sua população por idade e sexo, a cada ano desse período, por meio do emprego de um diagrama de Lexis, tomando-se como ponto inicial a população registrada até 1970, por idades simples e sexo, à qual foram sendo acrescentados, ano a ano, até 2007 , os nascimentos e emigrantes, e subtraídos os óbitos e imigrantes, nas idades em que esses eventos ocorreram. O diagrama de Lexis é um gráfico formado por uma trama de linhas paralelas e diagonais que representa, em duas dimensões, três variáveis demográficas: a data, a idade e o momento do nascimento, óbito ou qualquer outro evento demográfico, podendo assim representar a dinâmica de uma população 15 .

O volume anual da população obtido por meio dessa técnica serviu de base para estimar as seguintes medidas demográficas: taxas de crescimento médio anual; composição por idade e sexo; razões de sexo (RS); taxas brutas de mortalidade (TBM); taxas de mortalidade infantil (TMI); mortalidade proporcional e específica por sexo e idades, taxas brutas de natalidade (TBN); taxas de fecundidade total (TFT) e específicas por idades (TEF); média de idade ao nascimento do primeiro filho vivo; intervalos entre os nascimentos.

Para contornar as flutuações dos indicadores, resultantes do pequeno volume populacional, foram calculados indicadores médios para os períodos 1970-1979, 1980-1989, 1990-1999 e 2000-2007.

\section{Resultados}

\section{Evolução da população de 1970 a 2007}

As aldeias Kayabí do Parque Indígena do Xingu possuíam 204 habitantes em 1970, e 1.162 em 2007. Somados os Kayabí que se integraram às aldeias de outros povos do Parque Indígena do Xingu (18 indivíduos) àqueles que residem em áreas urbanas próximas ao parque, como Sinop e Canarana (45 indivíduos), onde participam da gestão do Distrito Especial Indígena do Xingu (DSEI-XINGU) e da Associação Terras Indígenas do Xingu (ATIX), a população Kayabí na região totalizava, em 2007, 1.225 indivíduos.

No período 1970-2007, a população Kayabí do Parque Indígena do Xingu aumentou 5,7 vezes, crescendo, em média $4,8 \%$ ao ano. $\mathrm{O}$ aumento populacional foi crescente, estabilizando-se em torno de 5,4\% ao ano desde a década de 1990 (Tabela 1). O crescimento vegetativo foi responsável pela quase totalidade do aumento populacional, sendo o crescimento migratório irrelevante a partir de 1973, quando os movimentos de entradas e saídas do Parque Indígena do Xingu 
Tabela 1

Resumo dos principais indicadores demográficos dos Kayabí do Parque Indígena do Xingu, Mato Grosso, Brasil, no período $1970-2007$

\begin{tabular}{|c|c|c|c|c|}
\hline Indicadores demográficos & 1970-1979 & 1980-1989 & 1990-1999 & 2000-2007 \\
\hline Taxa bruta de natalidade (por mil) & 46,3 & 52,9 & 55,9 & 51,0 \\
\hline Taxa bruta de mortalidade (por mil) & 11,4 & 8,6 & 4,6 & 3,5 \\
\hline Taxa de crescimento médio anual (por cem) & 3,3 & 4,8 & 5,3 & 5,4 \\
\hline Taxa de mortalidade infantil (por mil) & 45,0 & 52,4 & 17,8 & 17,5 \\
\hline Taxa de fecundidade total (média de filhos nascidos vivos por mulher) & 5,7 & 8,4 & 9,5 & 7,8 \\
\hline Contribuição das mulheres menores de 30 anos para a fecundidade total (\%) & 80 & 60 & 59,3 & 60,4 \\
\hline Média de idade ao nascimento do primeiro filho vivo (em anos) & 15,8 & 15,5 & 15,5 & 16,5 \\
\hline Intervalo médio entre os nascimentos vivos (em meses) & 34 & 32 & 29 & 30 \\
\hline
\end{tabular}

Fonte de dados brutos: Projeto Xingu, Departamento de Medicina Preventiva, Escola Paulista de Medicina, Universidade Federal de São Paulo.

(migração externa) e entre as aldeias Kayabí e as de outros povos habitantes do parque (migração interna) foram constantes, mas, insignificantes numericamente.

\section{Mortalidade}

A mortalidade geral observada entre os Kayabí declinou progressivamente ao longo do período 1970-2007, passando de 11,4 óbitos por mil habitantes no período 1970-1979 para 3,5 óbitos por mil habitantes entre 2000-2007 (Tabela 1).

Os níveis de mortalidade infantil foram bastante elevados nos períodos de 1970-1979 e 1980 1989: 45 e 52,4 óbitos por mil nascimentos vivos, respectivamente. A partir da década de 1990, a mortalidade infantil diminuiu acentuadamente, estabilizando-se em torno de 17,5 óbitos por mil nascimentos (Tabela 1).

No que tange à mortalidade proporcional do conjunto da população, as proporções de óbitos em menores de um ano de idade oscilaram entre $20 \%$ e $27 \%$ do total de óbitos nos quatro períodos analisados (Tabela 2). A proporção de óbitos na população de 50 anos e mais anos, inferior a $20 \%$ nas décadas de 1970 e 1980, foi mais expressiva na década de 1990 e no período 2000-2007, (34\% e $39 \%$, respectivamente), acompanhando o incremento da população nessas idades, como pode ser observado na análise da composição etária da população. No tocante aos sexos, chama atenção a alta proporção de óbitos na população masculina de 20 a 49 anos de idade na década de 1970 e a ausência de óbitos de maiores de 50 anos na população feminina nas décadas de 1970 e 1980 .

As taxas específicas de mortalidade do conjunto da população, nas décadas de 1970 e 1980, apontam para os mais altos níveis de mortalida- de na faixa etária de menores de um ano, respectivamente, 50 e 44,1 óbitos por mil habitantes (Tabela 2). De 1990 a 2007, é a população com 50 e mais anos que apresenta os mais expressivos níveis de mortalidade, que variaram de 19,5 a 21,8 óbitos por mil habitantes, por período. De modo geral, a mortalidade masculina é superior à feminina em quase todos os grupos etários. Destaca-se o baixo nível de mortalidade registrado nas idades de 5 a 19 anos, entre 1970 e 1990, e a ausência de óbitos neste grupo etário no período 2000-2007.

\section{Natalidade e fecundidade}

Na década de 1970, a TBN dos Kayabí era de 46,3 nascimentos por mil habitantes. A partir da década de 1980 esse índice cresceu continuamente atingindo 55,9 nascimentos por mil habitantes no período 1990-1999. Entre 2000 e 2007, a TBN declinou para 51 nascimentos por mil habitantes (Tabela 1).

A evolução dos níveis de fecundidade das mulheres Kayabí pode ser observada por meio das TFT, índice sintético que representa o número médio de filhos por mulher durante seu período reprodutivo (Tabela 1). Entre as décadas de 1970 e 1990, a TFT dessas mulheres aumentou de 5,7 para 9,5 filhos nascidos vivos, em média, por mulher, declinando para 7,8 filhos no período 2000-2007 (Tabela 1).

Na década de 1970, a estrutura etária da fecundidade identificava-se com o padrão “jovem”, com maior concentração entre as mulheres de 12-14, 15-19 e 20-24 anos de idade. A partir da década de 1980, o padrão etário da fecundidade foi mais "tardio", com concentração nas idades de 20 a 29 anos, confirmando o aumento da fecundidade das mulheres com idades superiores 
Mortalidade proporcional (por cem), taxas brutas e específicas de mortalidade por idade e sexo (por mil) dos Kayabí do Parque Indígena do Xingu, Mato Grosso, Brasil, 1970-2007.

\begin{tabular}{|c|c|c|c|c|c|c|c|c|c|c|c|c|}
\hline \multirow[t]{2}{*}{ Grupos etários (anos) } & \multicolumn{3}{|c|}{$1970-1979$} & \multicolumn{3}{|c|}{$1980-1989$} & \multicolumn{3}{|c|}{$1990-1999$} & \multicolumn{3}{|c|}{ 2000-2007 } \\
\hline & 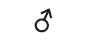 & 우 & Total & 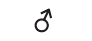 & 우 & Total & ठ & 우 & Total & 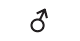 & 우 & Total \\
\hline \multicolumn{13}{|l|}{ Mortalidade proporcional } \\
\hline$<1$ & 13,0 & 40,0 & 21,2 & 28,6 & 25,0 & 27,0 & 10,5 & 40,0 & 20,7 & 23,5 & 27,3 & 25,0 \\
\hline $1-4$ & 13,0 & 10,0 & 12,1 & 19,0 & 37,5 & 27,0 & 15,8 & - & 10,3 & 17,6 & 9,1 & 14,3 \\
\hline $5-19$ & 13,0 & - & 9,1 & 14,3 & 12,5 & 13,5 & 15,8 & 10,0 & 13.8 & - & - & - \\
\hline $20-49$ & 34,9 & 50,0 & 39,4 & 14,3 & 25,0 & 18,9 & 21,1 & 20,0 & 20,7 & 23,5 & 18,2 & 21,4 \\
\hline $50 e+$ & 26,1 & - & 18,2 & 23,8 & - & 13,5 & 36,8 & 30,0 & 34,5 & 35,4 & 45,4 & 39,3 \\
\hline Total relativo & 100,0 & 100,0 & 100,0 & 100,0 & 100,0 & 100,0 & 100,0 & 100,0 & 100,0 & 100,0 & 100,0 & 100,0 \\
\hline Total absoluto & 23 & 10 & 33 & 21 & 16 & 37 & 19 & 10 & 29 & 17 & 11 & 28 \\
\hline \multicolumn{13}{|c|}{$\begin{array}{l}\text { Taxas brutas e específicas } \\
\text { de mortalidade }\end{array}$} \\
\hline$<1$ & 41,7 & 58,8 & 50,0 & 53,1 & 35,1 & 44,1 & 12,9 & 22,9 & 18,2 & 20,9 & 14,6 & 17,6 \\
\hline $1-4$ & 12,7 & 4,8 & 9,0 & 9,5 & 15,9 & 12,6 & 5,4 & - & 2,6 & 4,4 & 1,3 & 2,7 \\
\hline $5-19$ & 4,6 & - & 2,7 & 3,5 & 2,5 & 3,0 & 1,9 & 0,9 & 1,4 & - & - & - \\
\hline $20-49$ & 14,2 & 10,5 & 12,5 & 4,5 & 6,8 & 5,6 & 4,3 & 3,2 & 3,8 & 4,1 & 3,3 & 2,9 \\
\hline $50 e+$ & 43,5 & - & 37,0 & 19,7 & - & 14,0 & 34,3 & 11,8 & 21,8 & 20,5 & 18,4 & 19,5 \\
\hline TBM & 13,9 & 8,1 & 11,4 & 9,1 & 8,1 & 8,6 & 5,5 & 3,5 & 4,6 & 4,5 & 2,7 & 3,5 \\
\hline
\end{tabular}

TBM: taxa bruta de mortalidade.

Fonte de dados brutos: Projeto Xingu, Departamento de Medicina Preventiva, Escola Paulista de Medicina, Universidade Federal de São Paulo.

a 30 anos, que repercutiu no crescimento das TFTs. Consistente com a mudança de padrão etário da fecundidade de "jovem para tardio", observou-se que a contribuição das mulheres $<30$ anos de idade para a fecundidade total passou de $80 \%$, na década de 1970 , para, aproximadamente, $60 \%$, a partir de 1980 . A média de idade ao nascimento do primeiro filho vivo, que se manteve entre os 15 e 15,8 anos, de 1970 a 1999, aumentou para 16,5 anos em 2000-2007. No conjunto do período 1970-2007, o intervalo médio entre os nascimentos vivos oscilou entre os 29 e 34 meses (Tabela 1 ).

\section{Composição por idade sexo}

A evolução da estrutura por idade e sexo dos Kayabí do Xingu pode ser visualizada nas pirâmides etárias dos anos de 1970 e 2007 (Figuras 1 e 2). O formato irregular da pirâmide de 1970, que retrata as gerações de Kayabí sobreviventes naquele ano, reflete o pequeno volume da população e os altos níveis de mortalidade das seis décadas anteriores, com maior exposição do sexo feminino. Na pirâmide de 2007, de contorno mais regular e desenho compatível com o de populações jovens, destacam-se o estreitamento nas idades adultas e o prolongamento da cúspide até os 80 anos e mais, refletindo o aumento da longevidade da população.

No tocante à distribuição proporcional da população por grandes grupos etários, entre 1970 e 2007, o peso relativo dos menores de 15 anos de idade aumentou de $45,6 \%$ para $55,9 \%$ e a proporção da população de 50 anos e mais passou de $5,9 \%$ para $7 \%$ (Tabela 3 ).

Em 1970, a razão de sexos indicava haver, em média, 134,5 homens a cada cem mulheres na população (Tabela 3). Embora em declínio progressivo, a superioridade numérica da população masculina se manteve até o final da década de 1990, prevalecendo em quase todos os grupos etários. Em 2000 e 2007, já havia mais mulheres do que homens no conjunto da população (RS entre 90 e 95 mulheres a cada cem homens), o que se confirma em quase todas as idades, exceto do grupo etário 15-49 anos em $2000(\mathrm{RS}=116,5)$.

\section{Discussão}

Entre 1970 e 2007, a população Kayabí cresceu $4,8 \%$ ao ano, sendo o aumento vegetativo o principal responsável por este expressivo cres- 


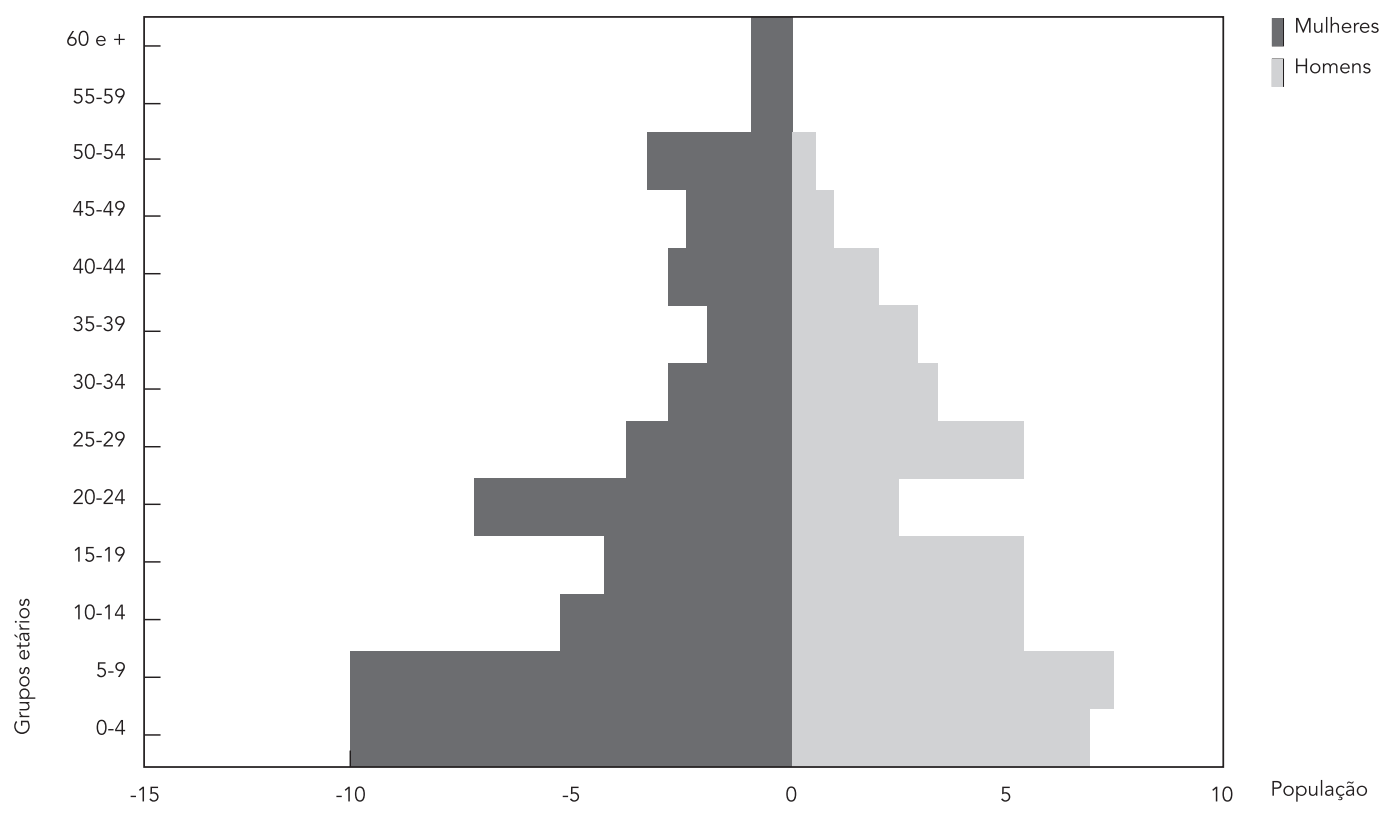

Fonte de dados brutos: Projeto Xingu, Departamento de Medicina Preventiva, Escola Paulista de Medicina, Universidade Federal de São Paulo.

cimento. A partir de 1973, quando se completou o processo migratório dos Kayabí de sua região de origem para o Parque Indígena do Xingu, o saldo migratório passou a ser numericamente irrelevante, devendo-se quase que exclusivamente às mudanças de aldeias dentro e fora do parque para fins matrimoniais.

Estudos demográficos sobre populações indígenas realizados nos últimos anos 16,17,18,19,20 confirmam que alguns grupos indígenas no país experimentaram flutuações em seus níveis de mortalidade e natalidade nas últimas décadas que, no longo prazo, resultaram em taxas de crescimento ( $3 \%$ e $5 \%$ ao ano) muito superiores às do conjunto da população brasileira. No período 1991-2000, a população da Região Centro-Oeste do país, onde se localizam as comunidades Kayabí, cresceu $2,4 \%$ ao ano 21 .

No conjunto da população Kayabí, a mortalidade geral declinou de 11,4 para 3,5 óbitos por mil habitantes, entre 1970 e 2007, o que pode estar relacionado à melhoria da atenção à saúde no Parque Indígena do Xingu, com um programa de imunização desenvolvido desde 1965, e à intensificação da formação de agentes indígenas de saúde em anos mais recentes. Para os Yanomámi do rio Mucajai 16, o declínio da mortalidade geral de 36,3 para 26 por mil habitantes, no período 1955-1985, seria explicado pela imunidade adquirida, esforços clínicos e preventivos do programa médico levado a efeito com o apoio de missionários, intensificação das campanhas de vacinação e diminuição dos contatos com a sociedade nacional.

Entre os Kayabí, a mortalidade geral sempre mais elevada entre os homens, declinou para ambos os sexos de 1970 a 2007. A sobremortalidade masculina registrada entre esses índios é uma tendência já observada em outros povos indígenas habitantes do Parque Indígena do Xingu 17.

A redução da mortalidade infantil entre os Kayabí no período 1970-2007 foi surpreendente (de 45 para 17,5 óbitos por mil nascidos vivos). O nível verificado nos anos $2000(17,5)$ pode ser considerado baixo se comparado aos valores encontrados em outras populações indígenas estudadas no Brasil, como os Xavánte que registram valores próximos a 100 óbitos por mil nascidos vivos 17. Não se conhece as TMI dos Kayabí para 


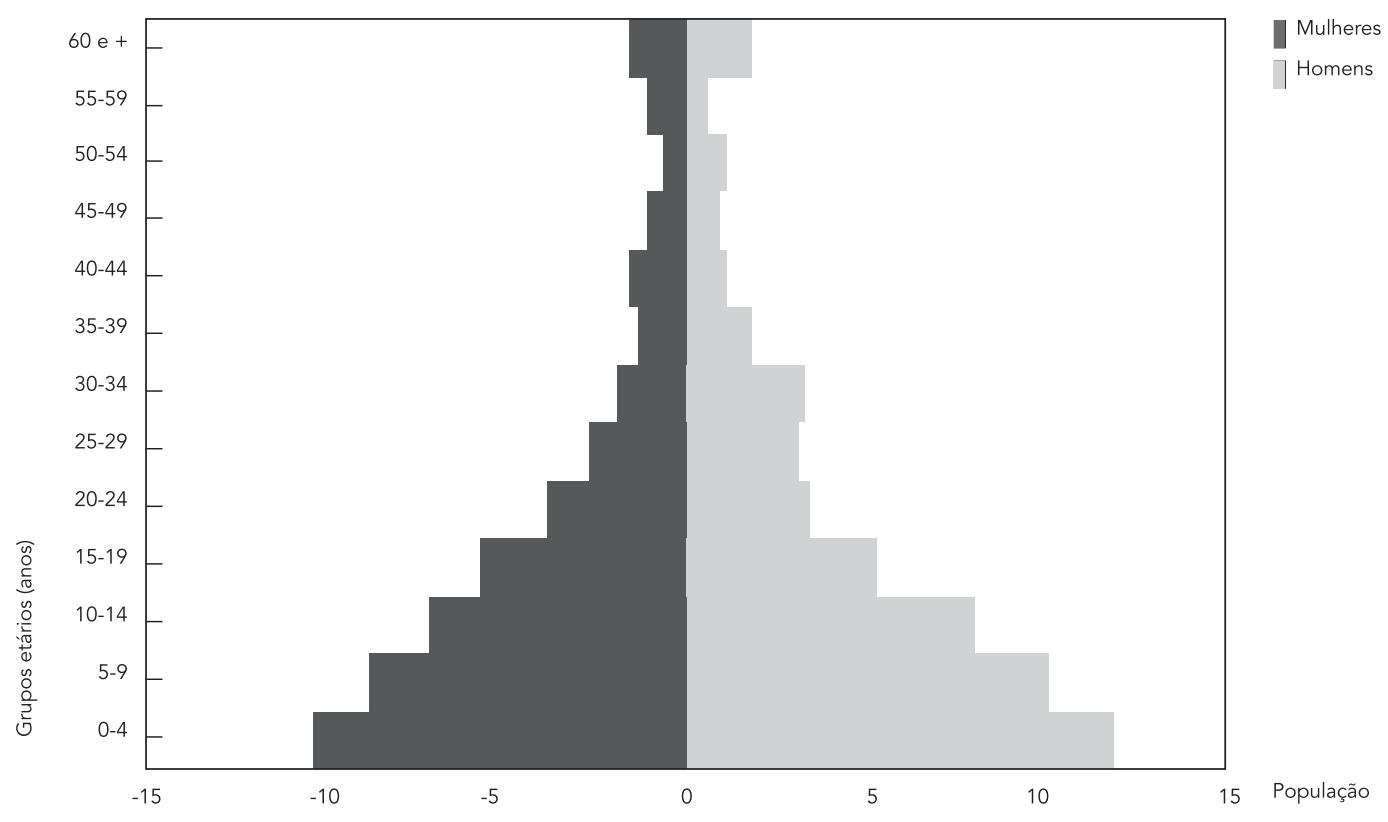

Fonte de dados brutos: Projeto Xingu, Departamento de Medicina Preventiva, Escola Paulista de Medicina, Universidade Federal de São Paulo.

o período de contato com as frentes expansionistas, mas, seria válido supor que teriam sido muito altas. Os registros de óbitos e de nascimentos dos postos do SPI destinados aos Kayabí são muito irregulares, não permitindo arriscar nenhuma estimativa para os mais de trinta anos em que esses índios estiveram sob sua tutela. Os depoimentos de alguns Kayabí do Xingu a respeito do período em que permaneceram sob a atenção do SPI mencionam muitas mortes por epidemias de sarampo e de gripe, infecções respiratórias e tuberculose, e enfatizam as mortes de crianças recém-nascidas.

O exame da mortalidade proporcional do Kayabí também aponta para a melhoria das suas condições de saúde nos anos 2000, com a manutenção da proporção de óbitos de menores de um ano de idade em torno de $25 \%$ e maior concentração de óbitos na população de 50 e mais anos (40\%). A mortalidade específica por idade desses índios é, desde a década de 1990, mais elevada na população de 50 ou mais anos, em torno de 20 óbitos por mil habitantes. Destaca-se o baixo nível de mortalidade registrado, principalmente no sexo masculino, nas idades de 5 a 19 anos, quando comparado à mortalidade específica por idades de outros povos do Xingu 18,19.

As taxas de natalidade dos Kayabí apresentaram tendência de aumento até o final da década de 1990 (55,9 nascimentos por mil habitantes) e de declínio entre 2000-2007 (51 nascimentos por mil habitantes), sendo similares às de populações indígenas que voltaram a crescer após longos contatos com não-índios. Entre os Xavánte, Souza 17 encontrou uma taxa bruta média de natalidade de 59,2 nascimentos vivos por mil habitantes entre 1999-2004.

O comportamento da fecundidade das mulheres Kayabí acompanha a tendência observada na natalidade, de aumento das TFTs de 5,7 para 9,5 filhos nascidos vivos, em média, por mulher, de 1970 a 1999 e de declínio no período 20002007 para 7,8 filhos, em média. O elevado nível de fecundidade das Kayabí na década de 1990 (9,5) foi próximo do registrado entre mulheres com fecundidade natural, como as Hutterites da América do Norte ${ }^{22}$. A melhoria das condições de saúde e de sobrevivência da população como um todo, e das mulheres em particular, foi fator importante no aumento da fecundidade registrado até a 
População por sexo, razões de sexo (por cem) e proporções por grandes grupos etários (por cem) dos Kayabí do Parque Indígena do Xingu, Mato Grosso, Brasil, 1970-2007.

\begin{tabular}{|c|c|c|c|c|c|}
\hline Indicadores & 1970 & 1980 & 1990 & 2000 & 2007 \\
\hline População total & 204 & 282 & 451 & 758 & 1162 \\
\hline Masculino & 117 & 153 & 234 & 369 & 552 \\
\hline Feminino & 87 & 129 & 217 & 389 & 610 \\
\hline Grupos etários (anos) & 100,0 & 100,0 & 100,0 & 100,0 & 100,0 \\
\hline$<15$ & 45,6 & 48,2 & 53,0 & 56,2 & 55,9 \\
\hline $15-49$ & 48,5 & 46,5 & 40,1 & 36,3 & 37,1 \\
\hline 50 e + & 5,9 & 5,3 & 6,9 & 7,5 & 7,0 \\
\hline Razões de sexo (anos) & 134,5 & 118,6 & 107,8 & 94,9 & 90,5 \\
\hline$<15$ & 132,5 & 126,7 & 104,3 & 83,6 & 87,0 \\
\hline $15-49$ & 115,2 & 98,5 & 115,5 & 116,5 & 95,0 \\
\hline $50 e+$ & 1100,0 & 400,0 & 93,8 & 90,0 & 95,1 \\
\hline
\end{tabular}

Fonte de dados brutos: Projeto Xingu, Departamento de Medicina Preventiva, Escola Paulista de Medicina, Universidade Federal de São Paulo.

década de 1990. Nesse sentido, a atenção voltada para a saúde da mulher, com programas específicos, principalmente para o período pré-natal, contribuiu para aumentar as possibilidades das mulheres conduzirem suas gestações a termo. $\mathrm{O}$ declínio da mortalidade em ambos os sexos proporcionou também maior duração das uniões conjugais, antes interrompidas com freqüência pela morte de um dos cônjuges, principalmente dos homens, cujos níveis de mortalidade são mais altos. A aquisição de maior equilíbrio entre os sexos na população também contribuiu para o aumento da estabilidade das uniões. Deve-se considerar também a possibilidade de melhora da qualidade das informações a partir da década de 1980, principalmente no tocante às idades e aos óbitos de recém-nascidos, como fator que contribuiu para o aperfeiçoamento das estimativas de fecundidade.

A introdução do conceito de planejamento familiar e de métodos anticoncepcionais hormonais, sob demanda, à população do Parque Indígena do Xingu no início da década de 2000, além do aumento da freqüência de doenças sexualmente transmissíveis, teria contribuído para a redução dos níveis de fecundidade das Kayabí no período 2000-2007 para 7,8 filhos em média. Resultados de exames colpocitológicos realizados em 217 mulheres Kayabí com idades entre 12 e 49 anos, em janeiro de 2007, indicaram a presença de Gardnerella vaginalis em 53,7\% destas mulheres, sendo as maiores prevalências encontradas em mulheres maiores de 25 anos de idade (Rodrigues D., 2007, comunicação pessoal).
O presente estudo mostrou também que a partir da década de 1990 houve um envelhecimento do padrão reprodutivo das mulheres Kayabí, evidenciado pela diminuição dos níveis de fecundidade das mulheres com até 24 anos e aumento nas idades superiores a 30 anos. A fecundidade passou a se concentrar nas idades de 20-29 anos tanto na década de 1990 como no início dos anos 2000, o que também foi registrado entre as mulheres Kamayurá 23, a partir da década de 1990, diferentemente do que vem ocorrendo entre as Suyá, que apresentam um rejuvenescimento da fecundidade 24 . O envelhecimento do padrão reprodutivo das Kayabí se confirma com o aumento da média de idade ao nascimento do primeiro filho vivo, estável até a década de 1990, em torno dos 15 anos, para 16,5 anos nos anos de 2000-2007. O intervalo entre os nascimentos vivos (intergenésico) se manteve curto, em torno de trinta meses, sendo semelhante ao encontrado em outras sociedades indígenas no Brasil, como os Mekranotire 25, os Karitiána 26, os Yanomámi do rio Mucajai 16, os Xavánte 17,20 , que também se caracterizam por curtos intervalos de tempo entre os nascimentos e aleitamento prolongado, podendo atingir até três anos.

O impacto das transformações demográficas ocorridas na população Kayabí repercutiu na mudança da sua composição por idade e sexo entre 1970 e 2007. A pirâmide etária de 1970, de formato bastante irregular, se transforma, em 2007, numa pirâmide de contornos mais regulares, compatível com o de populações "extre- 
mamente jovens". Os efeitos desse novo padrão demográfico se confirmam na distribuição da população por grandes grupos etários, com o aumento do peso relativo da população de menores de 15 anos de idade para 55,9\%. Estudos realizados nos últimos anos têm apontado para o crescimento da proporção da população de menores de 15 anos entre os povos indígenas que retomaram altos níveis de fecundidade e estão em fase de recuperação populacional, como os Xavánte 17,20 e os Suyá 18 .

A avaliação da composição por sexo das populações oferece elementos importantes para a compreensão de seu processo de reprodução, sobretudo no que tange ao potencial da população disponível para garantir a reposição populacional, à formação de uniões conjugais em sociedades monogâmicas ou poligâmicas, e ao desempenho de papéis e de funções por gênero na organização social e de produção. A inversão da razão de sexos dos Kayabí, de 134,5 homens a cada cem mulheres, em média, na década de 1970, para 90,5 homens a cada cem mulheres em 2007, estaria associada à persistência de níveis de mortalidade mais elevados na população masculina. Entre os povos do Alto Rio Negro 27,28, além dos Boróro 29 e Xavánte 17,20, há mais homens do que mulheres na população, indicando níveis de mortalidade mais altos para as mulheres.

\section{Considerações finais}

A história do isolamento dos Kayabí, pelo menos a partir do início do século XIX, numa área que se estende do Alto rio Teles Pires (Mato Grosso), na confluência do rio Verde, até o Médio curso deste rio, incluindo o rio dos Peixes, afluente do Arinos (Mato Grosso), poderia estar relacionada à expansão do território colonial e à descoberta e exploração de ouro na região de Cuiabá e, depois, nas proximidades do rio Guaporé. Essa pode ter sido a antiga morada dos Kayabí, se forem consideradas as evidências lingüísticas que incluem os Kayabí no grupo de fala Tupi da região do rio Madeira 30. Se os Kayabí se deslocaram do oeste para o leste do Mato Grosso em busca de refúgio ou se o seu território à leste (Teles Pires) permaneceu inexplorado durante séculos por possuir acidentes geográficos que dificultavam a exploração e "índios bravios" em seu caminho, são apenas suposições e talvez os reais trajetos dos antigos deslocamentos espaciais desses índios nunca venham a ser conhecidos.

A história recente dos Kayabí relata que a expansão da exploração seringalista no final do século XIX para o Alto Paranatinga e, no século XX, para o Alto e depois Médio Teles Pires, pro- vocou deslocamentos de suas aldeias e por vezes integração aos seringais, culminando com a mudança de uma parte do grupo para o Xingu, no início da década de 1950. A mudança fracionou ainda mais o grupo que, em 1950, já se encontrava disperso em aldeias locais. Ademais, acarretou também a perda de acesso a importantes recursos vegetais e animais presentes no antigo território que não são encontrados nas matas do Xingu, embora as roças das famílias que permaneceram no território ancestral não possuam mais determinadas plantas que foram preservadas pelos Kayabí do Xingu, nem mantenham a sua requintada e tradicional culinária 31 . Mas, a mudança preservou a língua e costumes, aspectos da identidade cultural hoje já esmorecidos entre os Kayabí do rio dos Peixes.

A saga desse povo não impediu que sobrevivessem, apesar de terem perdido na mudança a força política de outrora, depois resgatada com a recuperação populacional e a posição de destaque que hoje ocupam na região do Posto Diauarum no Parque Indígena do Xingu, onde representam mais de $50 \%$ da população total.

Entre 1970 e 2007, os Kayabí do Parque Indígena do Xingu, em franco processo de recuperação populacional, tiveram sua população aumentada de 204 para 1.162 habitantes, descontados os Kayabí e seus descendentes, que ao longo deste período foram se integrando a outros povos do Parque Indígena do Xingu. Contribuíram para esse elevado crescimento populacional, da ordem de 4,8\% ao ano, diversas circunstâncias favoráveis, como: o cessar de conflitos com frentes expansionistas da sociedade nacional, a menor exposição a epidemias e a garantia do território com a mudança para o parque do Xingu. A assistência médica também foi fundamental para a melhoria das condições de saúde com medidas preventivas e curativas.

As poucas malocas habitadas pelas famílias chegadas do antigo território a partir de 1952, distribuídas ao longo do rio Xingu, entre o Posto Diauarum e a confluência do Manitsauá-Missu, transformaram-se, em pouco mais de cinqüenta anos, em aldeias com mais crianças, adolescentes, adultos em idade de cuidar das roças fartas e de velhos mais longevos.

A composição etária da população, fragmentada e irregular em 1970, refletia a saga vivida pelos Kayabí por mais de cinqüenta anos em contato com seringueiros e postos do SPI, levando a mudanças constantes na tentativa de sobreviver e de preservar uma parcela do seu território. No início do século XXI, a sua estrutura etária é "excepcionalmente jovem" e revela o conjunto de mudanças demográficas dos últimos anos, que se configuraram no desencadeamento do pro- 
cesso de recuperação populacional. Apesar de ser muito jovem, a estrutura etária já aponta para um número maior de idosos.

Na década de 1970, as mulheres Kayabí representavam apenas $42,7 \%$ da população total. O desequilíbrio entre os sexos e o respeito às regras de parentesco inviabilizaram uniões e obrigaram alguns homens a procurar esposas entre os povos vizinhos. Com isso, alguns Kayabí viúvos e outros sem opção de cônjuges se casaram com mulheres não-Kayabí e contribuíram para o aumento populacional de outros povos do Parque Indígena do Xingu, o que foi importante para os Trumái, por exemplo, que corriam o risco de extinção. Atualmente, suas proles numerosas estão presentes nas aldeias de diversos povos do parque e as roças diversificadas e fartas complementam sua alimentação. Neste início de século XXI, a população feminina já representa mais de $50 \%$ do total, mudança que harmonizou o desequilíbrio entre os sexos outrora existente, aumentando as possibilidades de uniões conjugais entre primos cruzados prescritas pelas regras de parentesco dos Kayabí, contribuindo para a diminuição de casamentos interétnicos.

O equilíbrio numérico entre os sexos é fator fundamental para a formação das uniões conjugais em todas as populações. Para as sociedades indígenas, nas quais os sistemas sociais são complexos e as regras que regem as uniões conjugais prescrevem ou proscrevem casamen- tos com determinados parentes, esse equilíbrio é ainda mais relevante. Numa sociedade como a dos Kayabí, na qual a prática da poliginia não é freqüente, sendo apenas praticada por homens em situações de prestígio social - entre os chefes, por exemplo - um número de mulheres igual ao de homens é sempre desejável.

Os níveis de mortalidade, mais elevados entre os homens, declinaram para ambos os sexos durante esses trinta e sete anos. As taxas de mortalidade infantil, muito altas, até a década de 1980, atingiram nos anos 2000 níveis que podem ser considerados baixos para populações indígenas. Atualmente, os Kayabí abandonaram o infanticídio, como prática cultural, mas, no passado, sacrificavam os gêmeos, deficientes físicos e crianças geradas em uniões conjugais indesejadas socialmente.

Retomando a afirmação feita na introdução deste artigo, baseada em análise de Ribeiro ${ }^{5}$ sobre os efeitos dissociativos da depopulação de algumas sociedades indígenas no Brasil, de que, em condições não adversas, os padrões reprodutivos das populações indígenas são compatíveis com o tamanho mínimo de população que necessitam para se organizar social e culturalmente, conclui-se, com base nas medidas demográficas analisadas neste artigo, que os Kayabí vêm crescendo em população, o que tem permitido sua reprodução social.

\section{Resumo}

O artigo analisa a dinâmica demográfica dos Kayabí, povo de língua Tupi, do Parque Indígena do Xingu, Brasil Central, no período 1970-2007, com base em informações do registro de eventos vitais do Programa de Saúde da Universidade Federal de São Paulo no Xingu. O contato dos Kayabí com a sociedade nacional, na região do Alto rio Teles Pires, entre 1920 e 1950, deu origem a depopulação das aldeias por confrontos e epidemias de doenças infecto-contagiosas, resultando na emigração paulatina de alguns grupos Kayabí para o Xingu, onde até hoje vivem. Entre 1970 e 2007, a população Kayabí no Xingu cresceu 4,8\% ao ano, passando de 204 para 1.162 habitantes. No período 2000-2007, a taxa bruta de natalidade era de 51 nascimentos por mil habitantes, a de fecundidade total de 7,8 filhos por mulher, a taxa bruta de mortalidade de 3,5 óbitos por mil habitantes e a de mortalidade infantil de 17,5 óbitos por mil nascimentos. Na população, 56,2\% eram menores de 15 anos de idade. Os resultados mostram que, a exemplo do que vem ocorrendo com outros povos indígenas no Brasil, os Kayabí também estão se recuperando em população.

Índios Sul-Americanos; Dinâmica Populacional; Demografia 


\section{Agradecimentos}

Este trabalho é parte da Tese de Doutorado apresentada ao Programa de Pós-graduação da Faculdade de Saúde Pública da Universidade de São Paulo. Agradeço aos Kayabí, aos colegas do Projeto Xingu da Universidade Federal de São Paulo, e especialmente aos professores Roberto Geraldo Baruzzi, Maria Stella Ferreira Levy e à Jade Cury Martins, bolsista PIBIC do Conselho Nacional de Desenvolvimento Científico e Tecnológico (CNPq). A pesquisa recebeu recursos do CNPq por meio de Bolsa de Produtividade de Pesquisa.

\section{Referências}

1. Melatti JC. Índios do Brasil. São Paulo: Editora Hucitec/Brasília: Editora da UnB; 1993.

2. Ribeiro D. Culturas e línguas indígenas do Brasil. Educação e Ciências Sociais 1957; 2:5-102.

3. Gomes MP. Os índios e o Brasil. Ensaio sobre um holocausto e sobre uma nova possibilidade de sobrevivência. Petrópolis: Editora Vozes; 1991.

4. Instituto Brasileiro de Geografia e Estatística. Tendências demográficas. Uma análise dos indígenas com base nos resultados da amostra dos Censos Demográficos de 1991 e 2000. Rio de Janeiro: Instituto Brasileiro de Geografia e Estatística; 2005.

5. Ribeiro D. Convívio e contaminação. Efeitos dissociativos da depopulação provocada por epidemias em grupos indígenas. Sociologia 1956; 18:3-50.

6. Pagliaro H, Azevedo MM, Santos RV. Demografia dos povos indígenas no Brasil: um panorama crítico. In: Pagliaro H, Azevedo MM, Santos RV, organizadores. Demografia dos povos indígenas no Brasil. Rio de Janeiro: Editora Fiocruz/Associação Brasileira de Estudos Populacionais; 2005. p. 11-32.
7. Flowers NM. Crise e recuperação demográfica: os Xavánte de Pimentel Barbosa, Mato Grosso. In: Santos RV, Coimbra Jr. CEA, organizadores. Saúde dos povos indígenas. Rio de Janeiro: Editora Fiocruz; 1994. p. 213-42.

8. Clastres P. A sociedade contra o estado. São Paulo: Cosac \& Naify; 2003.

9. Junqueira C. Os índios do Ipavu. Um estudo sobre a vida do grupo Kamaiurá. São Paulo: Editora Ática; 1978.

10. Grünberg G. Os Kaiabi do Brasil Central. História e etnografia. São Paulo: Instituto Socioambiental; 2004.

11. Meliá B. Os Caiabi não-xinguanos. In: Coelho VP, organizador. Karl von den Steinen: um século de antropologia no Xingu. São Paulo: Edusp/Fundação de Amparo à Pesquisa do Estado de São Paulo; 1982. p. 486-509. 
12. Pagliaro H. A revolução demográfica dos povos in dígenas: a experiência dos Kaiabi do Parque Indígena do Xingu, Mato Grosso (1970-1999) [Tese de Doutorado]. São Paulo: Faculdade de Saúde Pública, Universidade de São Paulo; 2002.

13. Simões M. Os Txicão e outras tribos marginais do Alto Xingu. Revista do Museu Paulista 1966; 14: 76-104.

14. Kaiabi C. A história da minha vida. In: Ferreira MK, organizadora. Histórias do Xingu. Coletânea de depoimentos dos índios Suyá, Kayabi, Juruna, Trumai, Txucarramãe e Txicão. São Paulo: Núcleo de História Indígena e do Indigenismo, Universidade de São Paulo/Fundação de Amparo à Pesquisa do Estado de São Paulo; 1994. p. 85-115.

15. Welti C. Demografia II. México DF: Programa Latinoamericano de Actividades en Población, Universidad Nacional Autónoma de México; 1998.

16. Early JD, Peters JF. The population dynamics of the Macujaí Yanomama. Nova York: Academic Press; 1990.

17. Souza LG. Demografia e saúde dos índios Xavante do Brasil Central [Tese de Doutorado]. Rio de Janeiro: Escola Nacional de Saúde Pública Sergio Arouca, Fundação Oswaldo Cruz; 2008.

18. Pagliaro H, Carvalho NS, Rodrigues D, Baruzzi RG. Demographic dynamics of the Suyá, a Jê people of the Xingu Indigenous Park, Central Brazil, 19702004. Cad Saúde Pública 2007; 23:1071-81.

19. Pagliaro H, Junqueira C, Mendaña LGS, Mendonça SB, Baruzzi RG. Dinâmica demográfica dos Kamaiurá, povo Tupi do Parque Indígena do Xingu, Mato Grosso, Brasil, 1970-1999. Rev Bras Estud Popul 2008; 25:377-88.

20. Coimbra Jr. CEA, Flowers NM, Salzano FM, Santos RV. The Xavante in transition: health, ecology and bioanthropology in Central Brazil. Ann Arbor: University of Michigan Press; 2002.
21. Instituto Brasileiro de Geografia e Estatística. Tendências demográficas. Uma análise dos resultados da amostra do Censo Demográfico 2000. Rio de Janeiro: Instituto Brasileiro de Geografia e Estatística; 2004. (Coleção Estudos \& Pesquisas, 13).

22. Leridon $H$. Human fertility. The basic components. Chicago/London: University of Chicago Press; 1977.

23. Pagliaro H, Junqueira C. Recuperação demográfica e fecundidade dos Kamaiurá, povo Tupi do Parque Indígena do Xingu, Brasil Central, 1970-2003. Saúde Soc 2007; 16:37-47.

24. Pagliaro H, Mendonça SB, Carvalho NS, Baruzzi RG. Fecundidade e saúde reprodutiva dos Suyá (Kisêdjê). Aspectos demográficos e culturais. In: Anais do XVI Encontro Nacional de Estudos Populacionais. http://www.abep.org.br.

25. Werner D. Fertility and pacification among the Mekranoti of Central Brazil. Hum Ecol 1983; 1:227-45.

26. Meireles D. Sugestões para uma análise comparativa da fecundidade em populações indígenas. Rev Bras Estud Popul 1988; 5:1-20.

27. Azevedo MM. Demografia dos povos indígenas do Alto Rio Negro/Amazonas: um estudo de caso de nupcialidade e reprodução [Tese de Doutorado]. Campinas: Instituto de Filosofia e Ciências Humanas, Universidade Estadual de Campinas; 2004.

28. Machado M. Perfil de morbimortalidade dos índios Hupd'äh da Região do Alto Rio Negro, Amazonas, Brasil [Dissertação de Mestrado]. São Paulo: Universidade Federal de São Paulo; 2006.

29. Souza LG, Pagliaro H, Santos RV. Perfil demográfico dos índios Boróro de Mato Grosso, Brasil, 19931996. Cad Saúde Pública 2009; 25:328-36.

30. Galvão E. Encontro de sociedades: índios e brancos no Brasil. Rio de Janeiro: Paz e Terra; 1979.

31. Ribeiro B. Diários do Xingu. Rio de Janeiro: Editora Paz \& Terra; 1979.

Recebido em 10/Ago/2009

Versão final reapresentada em 18/Nov/2009

Aprovado em 22/Dez/2009 